\title{
Cómo hacer un estudio enfocado en pacientes con COVID-19, una experiencia con sonografistas cardíacos
}

Paula Andrea Cuartas González

Hospital Universitario Mayor MÉDERI. Bogotá DC. Colombia

\section{Correspondencia}

Paula Andrea Cuartas González

pauliscuartis@gmail.com

Recibido: $31 / 05 / 2020$

Aceptado: 01/06/2020

En línea: 31/07/2020

Citar como: Cuartas-González PA. Cómo hacer un estudio enfocado en pacientes con COVID-19, una experiencia con sonografistas cardíacos. Rev Ecocar Pract (RETIC). 2020 (Jul); 3 (2): 51-54. doi: 10.37615/retic.v3n2a16.

Cite this as: Cuartas-González PA. How to do a focus cardiac ultrasound to patients with COVID-19, an experience of cardiac sonographers. Rev Ecocar Pract (RETIC). 2020 (Jul); 3 (2): 51-54. doi: 10.37615/retic.v3n2a16.

\section{Palabras clave \\ $\triangleright$ Ecocardiografía \\ $\triangleright$ Estudio enfocado \\ $\triangleright$ Infección por COVID-19 \\ $\triangleright$ Elementos de protección personal}

\begin{abstract}
RESUMEN
En el contexto de la pandemia por el nuevo coronavirus COVID-19, la ecocardiografía, por sus características, versatilidad y costo-efectividad es una herramienta básica para la monitorización cardiovascular de pacientes críticamente enfermos. Sin embargo, el contacto estrecho con el paciente que implica la realización de la ecocardiografía puede asociarse con riesgo de contagio. Por esta razón las sociedades científicas han publicado estrategias de prevención para evitar la infección por coronavirus del personal sanitario durante la realización de pruebas de imagen cardíaca. En estas recomendaciones, destaca el uso del "estudio enfocado" como estrategia para limitar el tiempo de exposición del personal de salud y el uso de equipos de protección personal específicos que brinden una adecuada protección durante la realización de los estudios.
\end{abstract}

\section{Condiciones técnicas y recomendaciones durante la realización de un estudio enfocado}

La ecocardiografía es una técnica diagnóstica versátil y ampliamente utilizada en diferentes contextos como la unidad de cardiología, el área de urgencias, hospitalización y las unidades de cuidado intensivo, sin embargo durante su realización el operador tiene un contacto estrecho con e paciente (menor a 1 metro de distancia). De acuerdo con el mecanismo de propagación del nuevo coronavirus, esta característica hace que la ecocardiografía se asocie con un alto riesgo de contagio por COVID-19, ya que no se puede garantizar una distancia entre personas mayor a 1 metro de distancia. Por ello, los profesionales de la salud que utilizan el ultrasonido cardíaco (ecocardiografistas y sonografistas cardíacos) se encuentran en primera línea de batalla, exponiéndose a un alto riesgo de infección por COVID-19 cuando realizan ecocardiografías en pacientes con sospecha o con infección confirmada por este virus.
Las diferentes sociedades académicas (ASE ${ }^{(1)}, \mathrm{SISIAC}^{(2)}, \mathrm{SEIC}\left({ }^{(3)}, \mathrm{SEC}\right)$ han recomendado el uso de "estudios enfocados" o "POCUS" (point of care ultrasound) para la valoración ecocardiográfica de pacientes con sospecha o confirmación de infección por COVID-19, en los que se sospeche compromiso cardíaco. Estos estudios se podrían definir como estudios abreviados en los que se adquiere la información ecocardiográfica básica que permite valorar la estructura y función cardíaca del corazón con una menor cantidad de imágenes bidimensionales y registros Doppler y en los que se omite el uso de registro electrocardiográfico simultáneo. Este tipo de estudio permite limitar el tiempo de exposición del profesional de la salud a menos de 15 minutos, disminuyendo el riesgo de infección por COVID-19.

Por las características que tiene el "estudio enfocado", el sonografista cardíaco debe adquirir imágenes diagnósticas de calidad óptima, que cumplan con los criterios técnicos establecidos para la ecocardiografía (profundidad, frame rate, ganancia, orientación, número de latidos, velocidad de barrido, línea de base, escala, etc.). Durante la realización de los estudios se deben tener en cuenta las condiciones 
técnicas encontradas en las unidades de aislamiento como la adquisición de imágenes de pie y con luz encendida, la limitación en la ventana acústica en pacientes con obesidad, la ventilación invasiva y el decúbito supino. Las imágenes deben permitir contestar a la pregunta o indicación del estudio y, así, evitar volver a ingresar a las unidades de aislamiento para obtener imágenes adicionales aumentando el tiempo de exposición y aumentando el riesgo de infección.

Las sociedades académicas también recomiendan la asignación de un profesional de la salud con amplia experiencia en adquisición de imágenes ecocardiográficas para hacer los estudios enfocados en este tipo de pacientes, utilizar elementos de protección personal adecuados de acuerdo con el tipo de exposición, asignar un solo ecógrafo para realizar estos procedimientos y protegerlo con dispositivos contra salpicaduras; utilizar jeringas prellenadas con gel de ultrasonido y realizar todas las mediciones off-line directamente en la unidad de cardiología.

\section{Aspectos técnicos para destacar durante la realización de un estudio enfocado en pacientes con sospecha o con infección confirmada por COVID-19}

La realización de los estudios enfocados en realidad requiere mayor tiempo que una valoración ecocardiográfica convencional, ya que hay que planificar el ingreso en las zonas de aislamiento y el ecocardiografista debe colocarse su equipo de protección personal. La realización de esta fase previa de planificación es vital para garantizar las condiciones de seguridad ideales para los profesionales de la salud y los pacientes; orientadas hacia la prevención de infección por COVID-19 y el uso adecuado de recursos en los hospitales y unidades de cardiología.

\section{Verificación de condiciones de seguridad para la realización del procedimiento}

Este paso es previo al ingreso en la zona de aislamiento y fundamental para realizar un procedimiento con indicación apropiada bajo condiciones de seguridad:

1. Identificar la indicación del estudio o la pregunta a responder, obtener información demográfica básica del paciente, revisar si tiene ecocardiografías previas, y otro tipo de estudios (radiografía de tórax, tomografía computarizada de tórax, etc.), identificar los antecedentes patológicos, confirmar el estado de infección por COVID-19 y presencia de ventilación invasiva.

2. Identificar la zona de aislamiento en donde se encuentra el paciente para definir los elementos de protección personal a utilizar.

3. Presentar el caso al ecocardiografista que está asignado en la lectura de estudios para determinar si la indicación del estudio es apropiada. Una vez revisados estos aspectos se verifica que el paciente no se encuentre pronado para la realización del estudio.

\section{Planificación de la realización del procedimiento}

En este paso se verifica el flujo de trabajo de acuerdo con la zona de aislamiento, con el objetivo principal de evitar la contaminación cruzada de los pacientes y el personal de salud:

1. Se determina el número de procedimientos a realizar en cada zona de aislamiento, por recomendación de epidemiología se hacen primero los casos sospechosos y al finalizar se hacen los casos positivos. Se verifica previamente que no existan procedimientos de urgencia vital.

2. Se marca el equipo asignado para hacer los procedimientos en zonas de aislamiento (equipo de aislamiento) con los datos de los pacientes a realizar en la unidad de ecocardiografía antes de ingresar a la zona de aislamiento.
3. Se prepara el kit para procedimientos de acuerdo con la zona de aislamiento de los pacientes (Figura 1). Este kit contiene traje quirúrgico institucional, traje de bioseguridad completo, mascarilla KN95/FFP2, gorro, monogafas, careta de seguridad, polainas (calzas), dos pares de guantes, bata antifluidos.

4. Finalmente se verifica que todos los elementos de protección personal estén completos y se procede a ingresar a la zona de aislamiento.

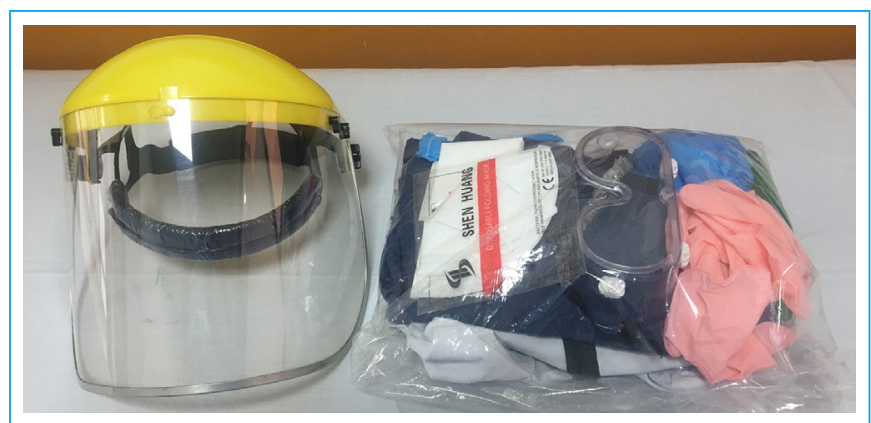

Figura 1. Kit de elementos de protección personal para la zona de aislamiento de pacientes con sospecha de infección o con infección confirmada por COVID-19

\section{¿Qué debe permitir el estudio enfocado?}

\section{El estudio enfocado debe permitir:}

- Realizar una valoración general de la anatomía y función cardíaca.

- Valorar el tamaño y función de las cavidades cardíacas.

- Evaluar con cuidado la función ventricular izquierda. Se debe hacer una valoración de la función global y la presencia de alteraciones de la contracción segmentaria que hagan sospechar cardiopatía isquémica.

- Valorar la función ventricular derecha. Determinar si hay signos que sugieran hipertensión y tromboembolismo pulmonar (TEP) agudo.

- Identificar la presencia de alteraciones de la función valvular.

- Valorar el pericardio y determinar si existe derrame pericárdico y su posible repercusión hemodinámica.

\section{Ejemplos de ecocardiografía enfocada en pacientes con COVID-19}

\section{Caso 1}

Varón de edad avanzada con infección confirmada sin ventilación invasiva. Se identifica insuficiencia aórtica importante (Vídeo 1, Vídeo 2 y Vídeo 3).

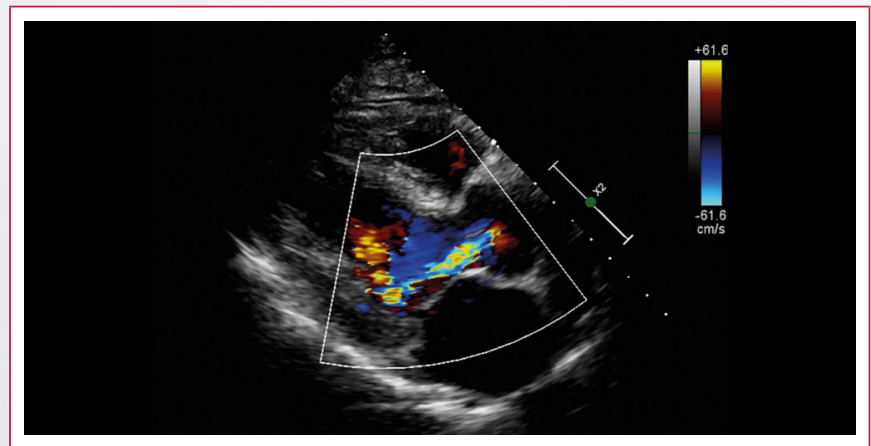

Vídeo 1. Plano paraesternal eje largo Doppler color que muestra insuficiencia aórtica 


\section{- Trukipedia truco 03}

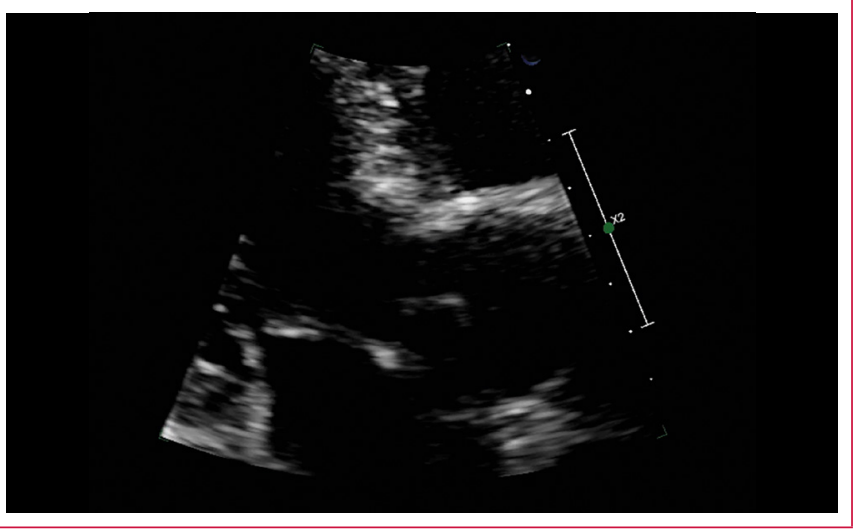

Vídeo 2. Plano paraesternal eje largo, zoom bidimensional de la válvula aórtica. Imagen filiforme adherida al borde libre de la válvula aórtica

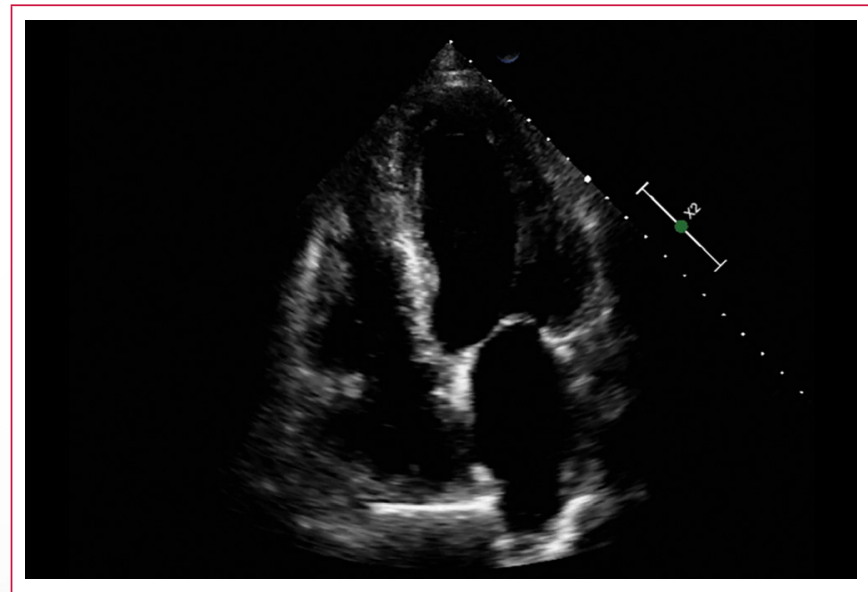

Vídeo 3. Plano apical de cuatro cámaras. Se observa adecuada función biventricular

Caso 2

Varón joven, con infección confirmada y ventilación invasiva, se identifica alteración de la función ventricular izquierda con disfunción sistólica leve (Vídeo 4 Vídeo 5 y Vídeo 6).

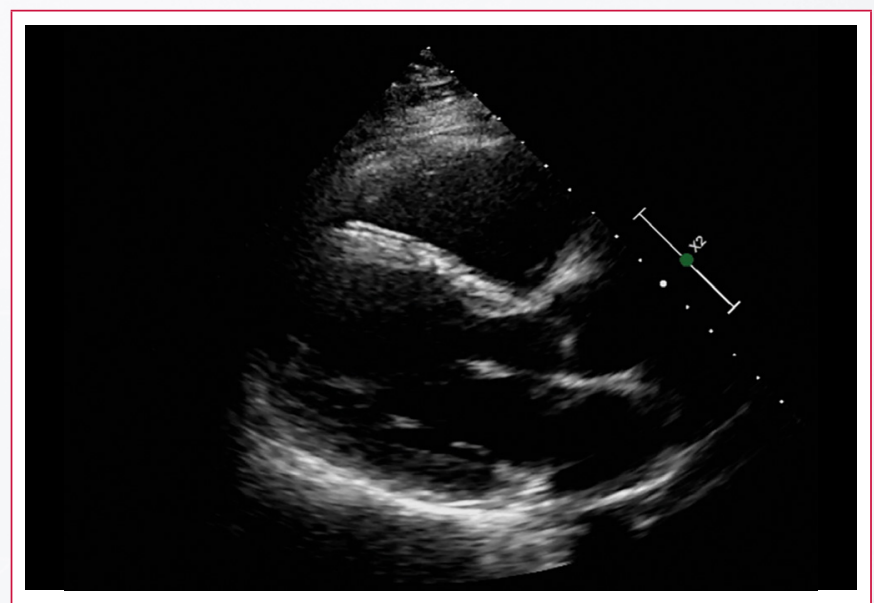

Vídeo 4. Plano paraesternal eje largo

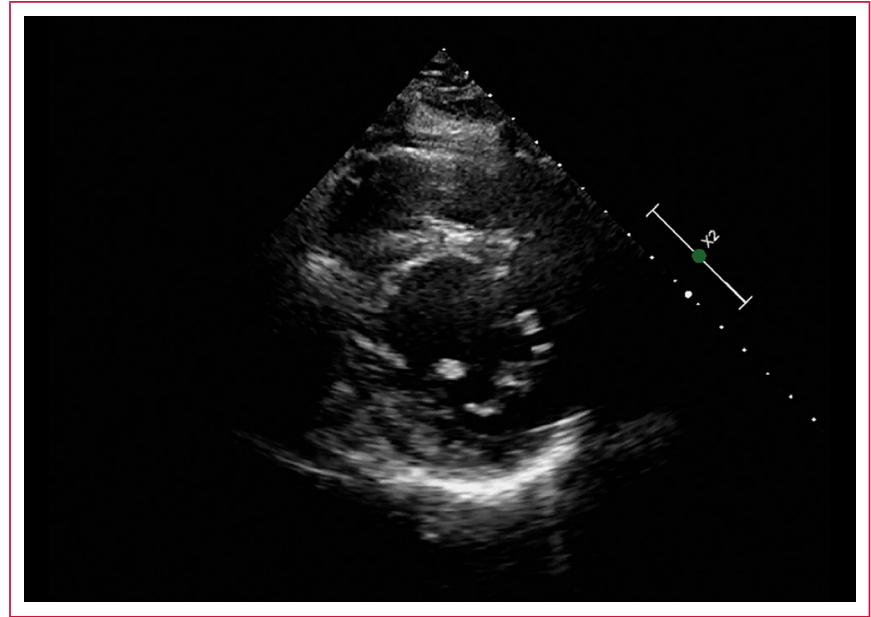

Vídeo 5. Plano paraesternal eje corto a nivel de músculos papilares

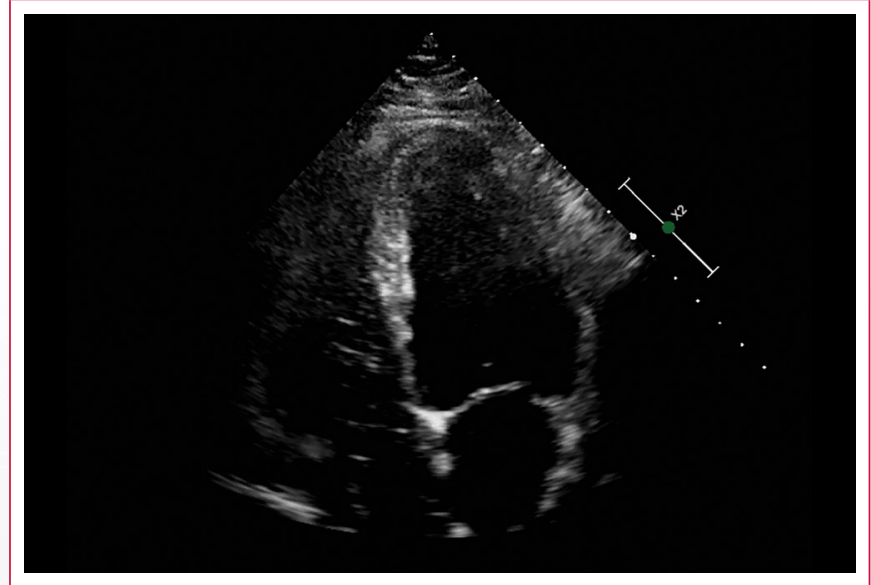

Vídeo 6. Plano apical de cuatro cámaras

Caso 3

Mujer anciana con infección confirmada, ventilación invasiva y diagnóstico de TEP segmentario (Vídeo 7, Vídeo 8 y Vídeo 9).

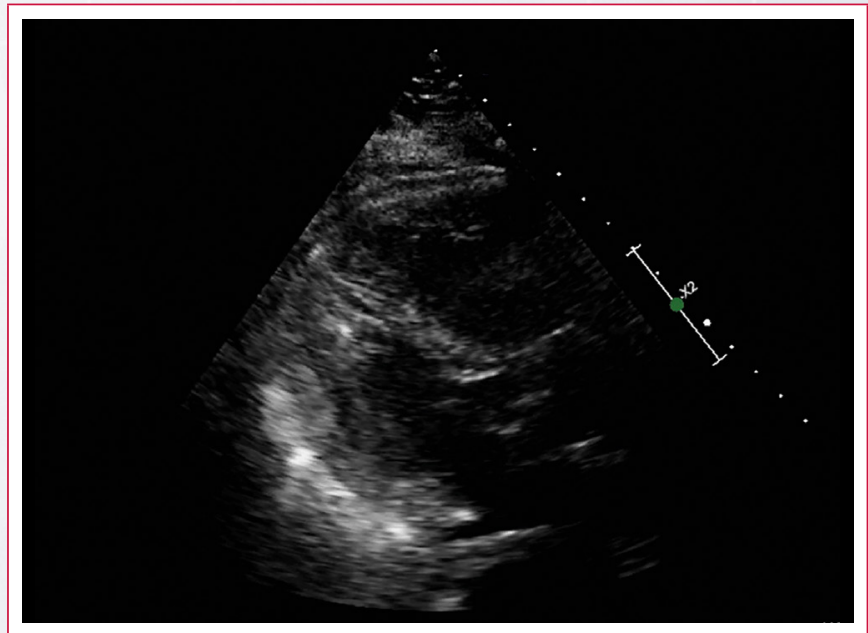

Vídeo 7. Plano paraesternal eje largo 


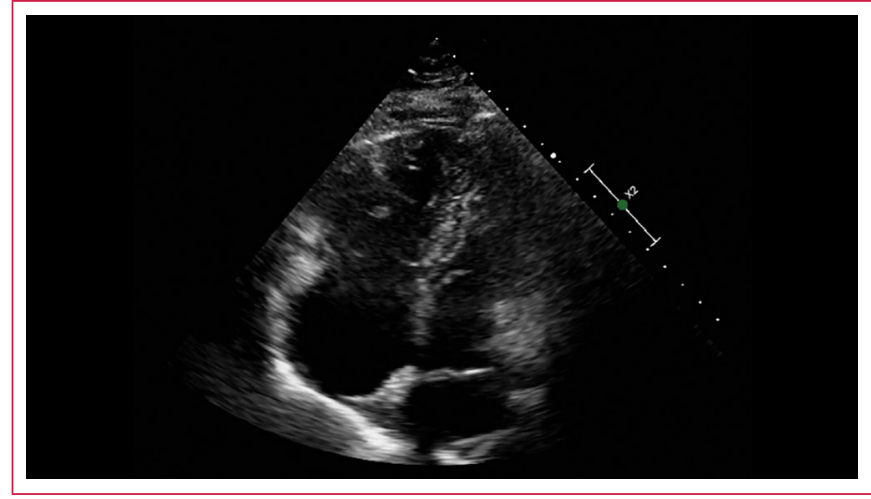

Vídeo 8. Plano apical de cuatro cámaras. Se observa aumento de tamaño del ventrículo derecho, movimiento paradójico del septum interventricular, desplazamiento hacia la izquierda del septum interauricular

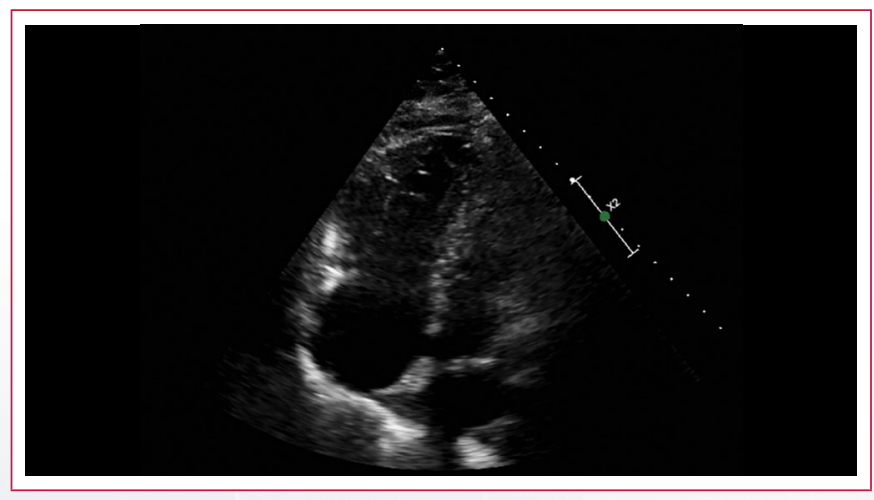

Vídeo 9. Plano apical de cuatro cámaras centrado en el ventrículo derecho. Se observa dilatación de cavidades derechas, disfunción del ventrículo derecho

\section{Ideas para recordar}

- El uso del "estudio enfocado" durante la pandemia por el COVID-19 permite hacer una adecuada valoración ecocardiográfica en pacientes que tienen indicación apropiada.

- La ecocardiografía enfocada limita el tiempo de exposición de los profesionales de la salud, por lo que disminuye el riesgo de contagio.

- Este procedimiento debe ser guiado por un protocolo específico en cada institución.

- Como para cualquier técnica ecocardiográfica, se debe desarrollar una curva de aprendizaje para una adecuada realización.

\section{Bibliografía}

1. Johri AM, Galen B, Kirkpatrick JN, et al. ASE statement on Point of care Ultrasound (POCUS) during the 2019 Novel Coronavirus Pandemic. American Society of Echocardiography. Disponible en: https://www.asecho.org/wp-content/ uploads/2020/04/POCUS-COVID_FINAL2_web.pdf

2. BOARD SISIAC. Estudio ecocardiográfico focalizado SISIAC para pacientes portadores o sospechosos de COVID-19. Marzo 2020. Disponible en: http://www. sisiac.org/ECO.Focalizado.SISIAC.COVID19.pdf

3. García Fernández MA, Azcarate Agüero P, Cabrera Schulmeyer MC, et al. Actualización de las recomendaciones sobre la logística de uso de la ecocardiografía durante la pandemia de COVID-19. Sociedad Española de Imagen Cardíaca. 2 de Mayo de 2020. Disponible en: https://ecocardio.com/documentos/covid-19/2125-actualizacion-recomendaciones-logistica-usoecocardiografia-pandemia-covid19.html 